\title{
Human Resource Management Practices: A Case Study of South Asian Countries
}

\author{
Rafique Ahmed Khan \\ Faculty of Management Science \\ Bahria University \\ Karachi, Pakistan \\ Mohammad Khasro Miah \\ School of Business \\ North South University \\ Dhaka, Bangladesh \\ Amir Manzoor \\ Faculty of Management Science \\ Bahria University \\ Karachi, Pakistan
}

\begin{abstract}
Purpose: The central point of this study was to demonstrate the similarity and difference of Human Resource Management (HRM) practices amongst the countries in South Asia. Through this paper, an in-depth study was undertaken to evaluate the validity of existing HRM practices in South Asian (SA) countries. An effort was made to examine the influences from the economic emergence in South Asia, force of colonization, historical panorama, cultural similarities and dissimilarities, legal, economic and political factors causing the change..

Methodology/Sampling: The study is based on secondary data collected through extensive research on present and past literature available on the topic.

Findings: HRM is in a reforming process towards the development of organizational transformation in South Asia. In addition, contextual and contingency factors are determining the outcome of restructuring HRM practices in South Asia, identified as FDI, foreign MNCs' influence, and bilateral relations among the SAARC members.

Practical Implications: Due to cultural impediments, organizations are finding it difficult to implement modern HRM practices in true letter and spirit. This study may draw some lessons for development and collaboration of novel opportunity of SAARC industries' HRM practices in South Asia.
\end{abstract}

Keywords: HRM Practices, SAARC, South Asia, Socioeconomic and Cultural Influence, Foreign Direct Investment (FDI), Multinational Corporations (MNCs).

\footnotetext{
*The material presented by the authors does not necessarily portray the viewpoint of the editors and the management of the Institute of Business \& Technology (IBT).

* Rafique Ahmed Khan: rak@bimcs.edu.pk

* Mohammad Khasro Miah: khasro@ northsouth.edu

* Amir Manzoor: amirmanzoor@bimcs.edu.pk

(C)MSS is published by the Institute of Business and Technology (IBT). Main Ibrahim Hydri Road, Korangi Creek, Karachi-75190, Pakistan.
} 
JEL Classification: E50, M12.

\section{INTRODUCTION}

South Asian context for Human Resources Management practices is someway a comparatively new approach for the management of entities operating in this region. Before the initial practices of labor management during the second decade of last century, the 'Human' related practices were not found in considerable number in Indian history. The beginning of personnel management can be referred back to the 1920s when there was emerging concern for the welfare of labor in factories. The official exposure to workers' unions was given by The Trade Union Act of 1926 (Pawan S. Budhwar, 2001). Managerial researches on human related activities in corporations have been practiced a lot by many scholars. Managing human resource is not an isolated or unknown practice of human life, like technical innovations and implementations in this modern world. When there was no technology or the logical advancements, the human led their lives and learned to live in peace; also conquered superior states where germane. So, all the studies have shown interlink between the learned behavior of HRM practices in this Indian region and the developed theoretical approaches of this business issue.

\subsection{HRM in Distinctive Style}

The labor related issues are always prominent in SA, as the developmental factors are constantly depending on the muscle power of the inhabitants. Technological advancements are adopted from the developed countries for eternity. South Asian industries are using more human capital as an input, related to the developed countries' automated systems for production. So, the managers of SA have developed several styles to control and supervise a large number of workers to keep the economic wheel in operation. While autocratic management style has been developed historically in this region (M. Khasro Miah, 2003), many adoptive techniques have been used to motivate workforce since the historic era. The colonial rulers' intention was to develop a style where the workforce will continue to work without any question for compliance of any rules they imply on the workforce. But historically, the people of these regions are resistant to change and they try to protest anything minimizing their interest and authority. The implementation of distinctive HRM style was possible to this region only because of the mind-set of foreign rulers in the subcontinent.

\subsection{Development of HRM in Indian Sub Continent}

The first pioneer book of Global stature on management, titled 'Arlhãshastra', that appeared about three millennia before Christ, outlined different facets of human resource practices in Ancient India (Chatterjee S. R., 2007). Monetary supervision of the state presented notions by this exposition which is appropriate for trade and commerce guiding principles, as well as the administration of employees (Rangarajan, 1992). Institutional thinking was to be surrounded based on these ideas for centuries (Sihag, 2004). The trade growth, with the involvement of Romans, led to extensive and well organized methods of governance by 250 A.D. The Gupta Dynasty which was the first Indian empire inspired for managerial systems during next 300 years based on the establishment of set of laws. Islam influenced many areas of trade and commerce (Chatterjee S. R., 2007). Indian managerial practices had a great impact of British corporate system for almost two hundred years. The bases of Indian socio 
cultural roots are widespread, with much of the input from various part of the world. The Indian system of cast and creed is one of the most significant sphere of values and cultural practices. This system maintained a traditionally oriented social or organizational balance. As per hierarchy of this caste system, Brahmins (priests and teachers) were at the top, whereas Kshatriya (rulers and warriors), Vaishya (merchants and managers) and Shwdra (artisans and workers) belonged to lower inferior levels in the same falling order. There were also some people outside the caste system who were known as 'untouchables'. Many decades ago, the influence of this caste system was so strong that some people belonging to a particular caste were able to dominate a typical public enterprise department. There were quite negative results of the caste system on managerial activities, especially during hiring, promotions and task distribution (C. Venkatratnam, 1996).

In the context of Indian traditions, the choice about whether to follow an individualistic or collectivistic behavior approach depends, to a large extent, on a number of variables that are influenced purely by the culture (Deyo, 1989). These variables are also regulated by three key elements guiding Indian managerial mindscapes. The three constructs are The Location (Desh), The Time (Kaal) and The Specific Persons Involved (Patro). Different scholars have claimed that association within these variables outlined the guidelines for decisional cues (Kannungo\& Sinha, 1997). This managing or nurturing of the outer layer of collectivism in an inner private sphere of individualism is expressed in Figure 1 (Sharma \&Khandekar, 2005), which explains the behavioral anchors in Indian organizational life.

Figure 1

Behavioral Anchors in Indian Organizational Life

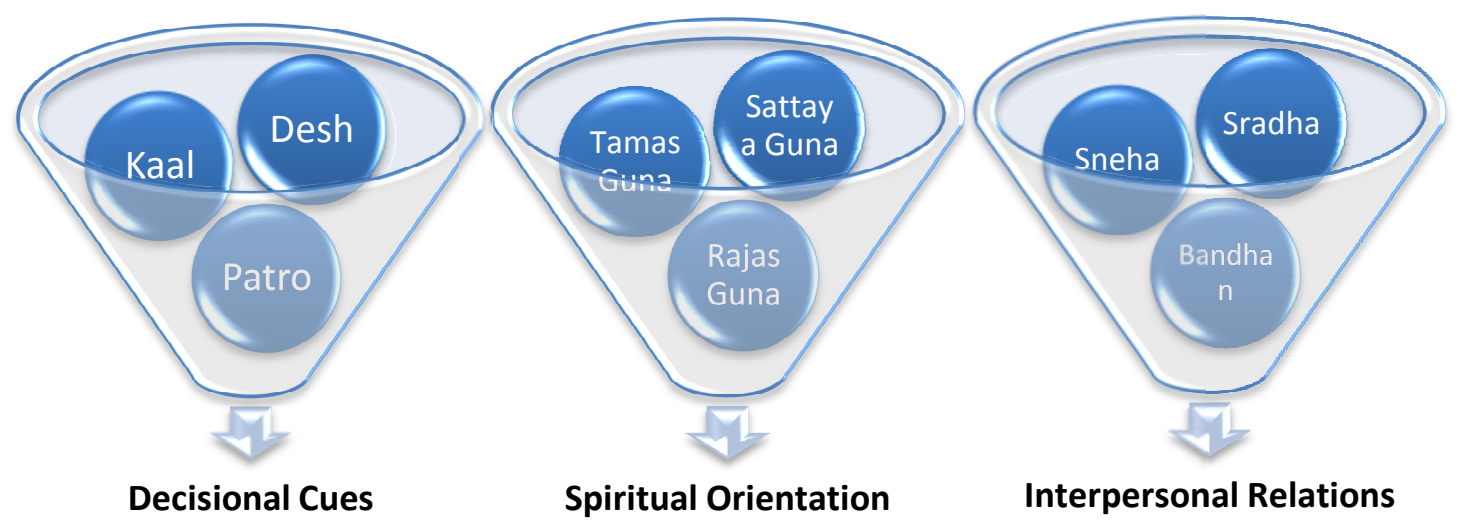

Figure1 indicates the strong impact of Indian tradition about the idea of 'guna' dynamics. This framework is being practiced in its three forms of gunas (attraction), and is gradually used in employee judgment and intuitional team developing strategies (Kuruvilla, 1996). The controversy is that each guna has a separate input in core personalities of human being. The Sattaya (or truth orientation) encompasses high ranking values of humans, intuitions and even the world at large. On the other hand, the Tamasikguna points at the negative orientation which can be expressed in behavior form such as unawareness, greed or dishonesty. People following a Rajasikguna are naturally driven by a desire to make a considerable value addition to their surroundings. Together, these spiritual orientations, such as Sattaya, Tamas and Rajas gunas, are expressed as constructive or destructive HR functions which include leadership practices, motivation interventions or IBT Journal of Business Studies (Formerly Journal of Management \& Social Sciences) 
other activities related to human behavioral. By looking at the last sector, it seems connected to HRM style of the society. The civilization root was derived by behavioral anchors which sketched the ethnicity of Sradha (upward loyalty) and Sneha (mentoring with affection). Young people have more inclination towards 'Sradha' whereas senior people appear to have more inclined towards 'Sneha'. In the context of Japanese organizational culture, this can be easily related to the concepts of 'Oyabun' and 'Kobun'.

\subsection{Moving to New Era of HRM in South Asia}

The long standing diverse notion about the different set of values that every society possesses is being challenged in South Asian. A promising governing perspective is that technological advancements have an influence on globalization which leads to business, education, and communication. Infrastructures have a leading impact on mindsets of management and business attitudes. As a result of global imperatives, striking changes have taken place for commercial mindsets and HRM strategies. In fact, the emerging competitive trends in the service sector have strongly demanded a demographic shift in worker qualification, education standard, relevant skill-set and diversification at regional level. Consequently, a marked shift towards importance of human resource in South Asian organizations has been visible because they have increasingly become strategy driven as opposed to the culture of maintaining the traditional status quo. As such, organizations are trying to achieve a sustained competitive edge in the software, pharmaceuticals, garments and biotechnology industries. These facts have been recently confirmed by three global South Asian companies who conducted a comprehensive research (with 235 managers); the evidence has reflected positive link between the HRM practices and organizational performance (Sharma \&Khandekar, 2005). Despite the fact that the trend of convergence appears to be more acceptable than ever before, still there is a clear shift towards locality-based orientation.

Figure 2

Drivers of Contemporary Indian HRM Trends

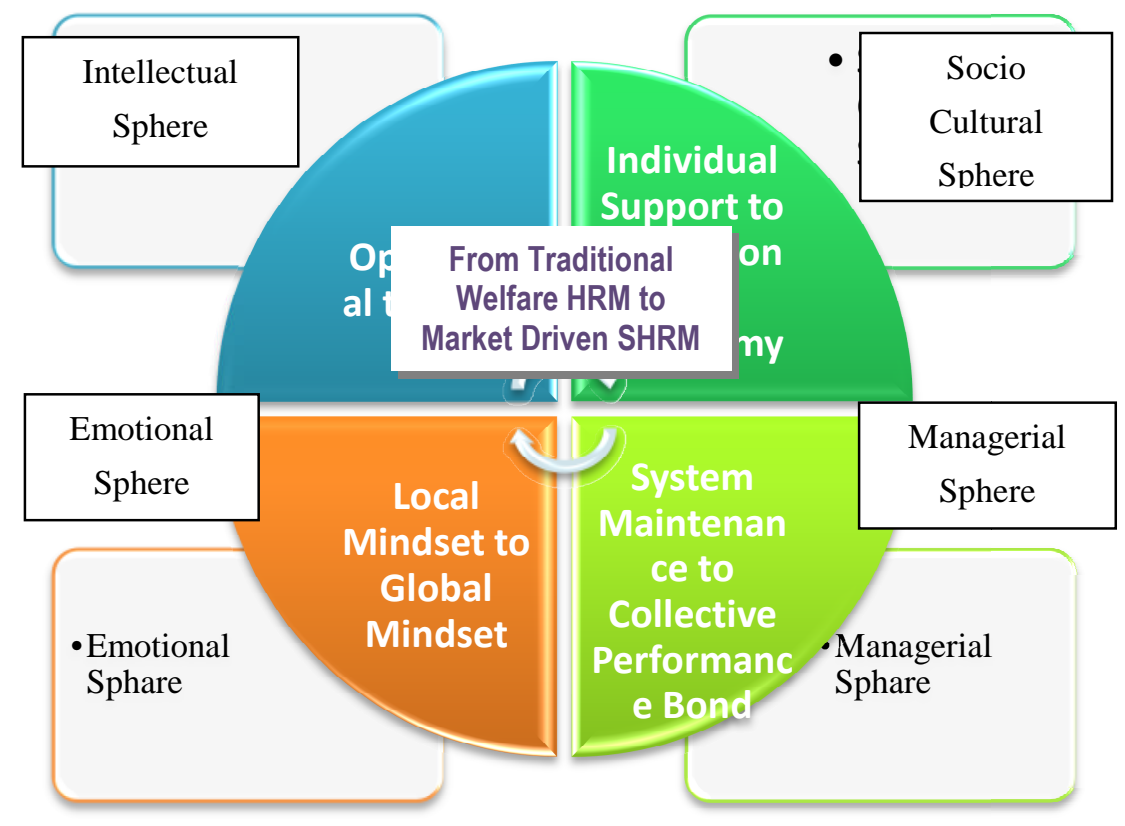


The key drivers of current Indian HRM trends, which are demonstrated in Figure 2, indicate that HRM professionals are being affected by four external spheres of intervention. These spheres have been incorporated in a composite arrangement within an organizational framework. The intellectual sphere seems to be strongly influenced by the global forces.

Empirical evidence, from 421 senior Indian managers, has indicated that in Indian society, many traditional values like respect for senior people, position status and association with influential group have been replaced by new dimensions which are usually linked with trends of globalization (Chatterjee \& Pearson, 2000). A significant attribute of the study, linked with employee work, was the opportunity given to employee to learn new things. Such trends deserve to be deeply understood with wider perspective because HR experts and practitioners are facing new realities of HR development after the post industrial transformations in the business world.

The remaining three sectors of Figure 2 are related to 'the emotional', 'the socio cultural' and 'the managerial' domains, which are facing similar transformation. Taking example of the socio cultural area, it confronts the dialect of the national macro level reform agenda as well as the challenge of innovation by addressing the hygiene and motivational features of the work place. As a result, this area is underpinned by the anchors of Sradha and Sneha which has the advantage to influence work by setting innovation in magnitude of sovereignty, autonomy and multi tasking. Also the poignant field that influences innovation to summarize the philosophy of workplace promise and group effort and constructive cooperation, brings enviable behavioral fundamentals of clearness and truthfulness into managerial events and practices. The administrative orb gives the mechanisms for changing mindsets because in South Asian organizations, HRM is viewed to be intimately associated with supervisory mechanical capability. Hence, in South Asian firms, indulgent of the relativity of HRM to policy projected managerial act is not sufficiently expressed.

\subsection{Management Impact of HR Practices in SA: Historical Reasons}

In 1980s, the enlarged globalization of markets and amplification of rivalry manifested the appearance of the concept of modern of human resource management (HRM). This latest taxonomy was discussed in academics and managerial writings in the USA for the 1st time (Peters and Waterman, 1982), (Tichy, Fombrun, \&Devanna, 1982) and in UK (Hendry \& Pettigrew). The practice of strategic human resource management (Guest, 1987) was quite different from the traditional administration. Undeniably, the transformation was significant in terms of expressions for regulating the employment relationship in UK and United States. Particularly, it was ascribed to a number of changes in both manufactured goods and labor markets, leading to different terms e.g. strengthening of global rivalry, globalization, culture of distinction, expertise revolution, and venture.

In early 1990s, South Asian companies followed a number of major cost-effective liberalization programs. In response to the torpid demand for production, the employers typically introduced flexi timings and cut down labor costs by reducing permanent labor force. Here two strategies were followed: make maximum use of the contract labor on shortterm basis and outsource part of production to other firms. For instance, in India the manpower, known as the careless, increased from 23\% (in1971) to 35\% (in 1991). Outsourcing of various activities including production, has lot of impact on regular employment which can determined from the fact that employment in manufacturing units during 1972-87 increased at an average annual rate of 1.44\% 
as compared to $4.57 \%$ increase in non-organized manufacturing, comprising of those units which employed fewer than 20 workers, and hence, not coming under the purview of the Factory Act (Sen Gupta \& Sett, 2000).

\section{PRESENT HRM PRACTICES OF SOUTH ASIA}

Managers in South Asian organizations motivate employees based on the company policies apart from the standard managerial norms or cultures practiced in industrially developed countries. The managers are nurtured from their own style of managing workforce in the industries to control. The persons behind uniting the workforce in a certain entities do not follow the matters relying on the needs of the people. So, the managers engaged in managing the workforce cannot believe in the standard HRM beliefs drawn from Western countries into the SA culture because of different cultural orientation of the workforce. While the managers are very polite and helpful towards their family and the society they belong to, they become very offensive and autocratic in the working environment. The reason is not too tough to investigate.

As mentioned by M. K. Gandhi (Bhatnagar, 2007) at the beginning of 21st century, the core population of India lived in its villages. As per statistics of the Indian census conducted in 2001, 74\% of Indians live in over 638,365 different villages (Registrar General $\&$ Census Commissioner, 2007). The villages vary in size and population and are not alike. In 236,004 villages, there are fewer than 500 inhabitants, but at the same time, in other 3,976 villages, more than 10, 000 people live. Most villages are the root of all economical and administrative activities in all over the India. The M.K. Gandhi had drawn the picture of independent India just after the Second World War, dividing the subcontinent into Hindu majority India and Muslim majority Pakistan (East and West).

Usually, all activities have been drawn from the culture of the central village administration. In earlier times, the villagers were the source of all power in all over the India. The administration was always centered by the village leader. It also reflected into the family structure. The head of the family had to take all decisions of the family, as he was the leading family earning source. Offspring of those family cultures had developed the style of autocracy. They have shifted the culture into the modern industry from their early family days. Once the power has to be allocated, all will look for the highest possible post suitable for them to control others. Here, people like to be directed by their superior, as in this case they have to take fewer responsibilities. So, the autocratic culture in management has developed in South Asian indigenous firms very quickly. Managers in the authority do not want to make them responsible for their decisions. The superiors always direct their juniors to formulate decisions and put up for perusal by the formers. There is a huge gap in this way of taking and implementing decisions. In the following Figure, this process will be further cleared in a more elaborate form. 
Figure 3

Decision flow and communication inside an organization

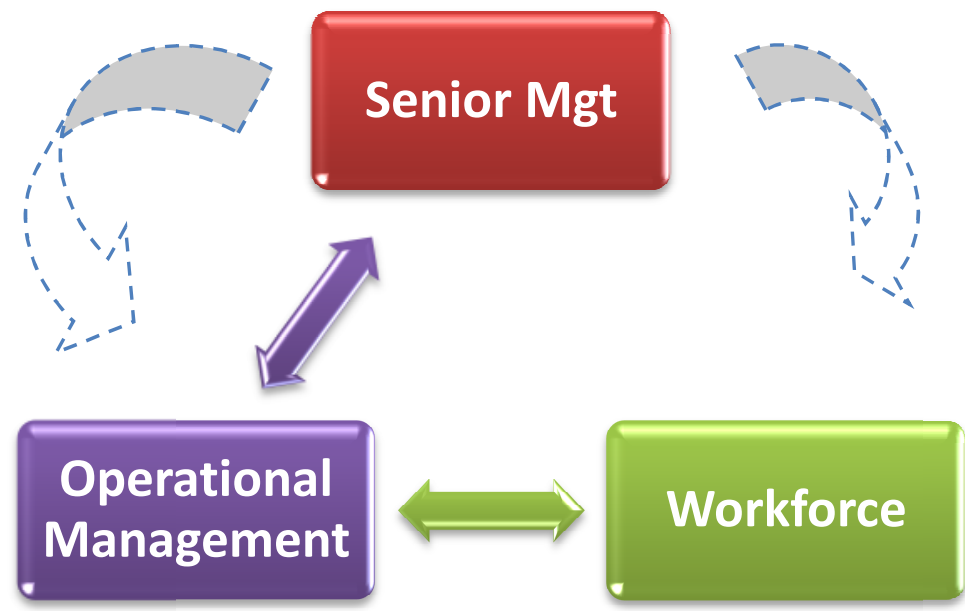

\section{Communication Flow Decision Flow}

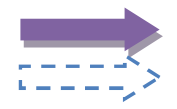

Generally, decisions are formulated by the operational management and are then approved by the senior management. Here, the workforce implements decisions formulated by the operational management and approved by the senior management. In this process there is a very large loophole due to lack of input by the subordinates. As the operational management formulates a decision, the senior management has the discretion to charge operational management and in contrast, the operational management is not approving the decision. Consequently, operational management can deny their responsibilities about the outcome of the decision which leads to lack of ownership.

In this procedure, the senior management becomes authoritative whereas actual implementation of decisions is ensured through operational management. As investigated earlier, the management positions are too vulnerable to accuse one another about any single decision they wish to take. The management can easily reject their duty assigned by the superior authority. Human behavior changes here in SA managerial environment as the managers find less trust and more dependency on others. These issues have ignited the people to be offensive and less trustworthy inside the organization, apart from their polite and reliable family life.

\subsection{South Asian Indigenous HRM Practices}

Studying South Asian HRM style is not very easy and a stand-alone approach. The inner style and practices may vary but the core issues are nearly same in almost all SA countries. Managers in this region are always keen to develop their expertise and the skills based on the issues that they learn from the gathered experience. Though the practices of South Asian firms are not far different from each other, most of the firms follow certain unique policies to run their organizations in an approach related to the HRM style. A comparative statement of different HRM practices being followed in SA countries is appended below: 
Table 1

Existing Practices of HRM in South Asian Countries

\begin{tabular}{|c|c|c|c|}
\hline Country & Frequent HR Practices & Examples & Key Issue \\
\hline Bangladesh & $\begin{array}{l}\text { Job Description } \\
\text { Recruitment } \\
\text { Training/ Development } \\
\text { Promotion \& Rewards } \\
\text { Gender Equity }\end{array}$ & $\begin{array}{l}\text { Defining the job and its responsibilities } \\
\text { Following a structured way of } \\
\text { Recruitment } \\
\text { Meeting the industry demand for T\&D } \\
\text { Based on performance \& experience } \\
\text { Usually for many posts it is equal }\end{array}$ & $\begin{array}{l}\text { Following true HRM } \\
\text { practices is not } \\
\text { possible for many orgs } \\
\text { here, because the } \\
\text { management follows } \\
\text { its } \\
\text { experience }\end{array}$ \\
\hline Bhutan & $\begin{array}{l}\text { T\&D } \\
\text { Skills Management } \\
\text { Performance Improvement } \\
\text { Process Improvement }\end{array}$ & $\begin{array}{l}\text { Central training initiatives } \\
\text { Measuring unique skills } \\
\text { Monitoring and evaluation } \\
\text { Close monitoring on the work process }\end{array}$ & $\begin{array}{l}\text { Monitoring human } \\
\text { development in the } \\
\text { country and being } \\
\text { successful in activities }\end{array}$ \\
\hline India & $\begin{array}{l}\text { Job Description } \\
\text { Recruitment } \\
\text { Compensation } \\
\text { Training/ Development } \\
\text { Performance Appraisal } \\
\text { Promotion and Rewards } \\
\text { Gender Equity }\end{array}$ & $\begin{array}{l}\text { Formally defining the job } \\
\text { Following a structured way of } \\
\text { Recruitment } \\
\text { Based on high performance; on the } \\
\text { merit } \\
\text { Security and lifetime employment } \\
\text { Institutionalized training } \\
\text { Low coverage of formal action } \\
\text { Moderately variable across industries } \\
\text { Usually admissible by court ruling }\end{array}$ & $\begin{array}{l}\text { Retaining workforce } \\
\text { based on the visible } \\
\text { performance r and } \\
\text { compensating by } \\
\text { direct monetary } \\
\text { rewards }\end{array}$ \\
\hline Maldives & $\begin{array}{l}\text { Training/ Development } \\
\text { Skills Management }\end{array}$ & $\begin{array}{l}\text { Employee Training Need Assessment } \\
\text { (TNA) } \\
\text { Enhancing employee skills }\end{array}$ & $\begin{array}{lr}\text { HR Policies are } \\
\text { dependent } & \text { on } \\
\text { traditional beliefs } & \end{array}$ \\
\hline Nepal & $\begin{array}{l}\text { HR Planning } \\
\text { Recruitment } \\
\text { Performance evaluation } \\
\text { Rewards }\end{array}$ & $\begin{array}{l}\text { Forecasting future needs } \\
\text { Hiring right type of employees } \\
\text { Raw and theoretical evaluation } \\
\text { Compensation on basis of performance }\end{array}$ & $\begin{array}{l}\text { Partially depending on } \\
\text { the managerial } \\
\text { activities as still the } \\
\text { base is agricultural } \\
\text { labor }\end{array}$ \\
\hline Pakistan & $\begin{array}{l}\text { Job Description } \\
\text { Recruitment } \\
\text { Compensation } \\
\text { Training/ Development } \\
\text { Performance Appraisal } \\
\text { Promotion and Rewards }\end{array}$ & $\begin{array}{l}\text { Minimal approach to defining a job } \\
\text { Shifting to HRD to recruit } \\
\text { Based on merit/ service } \\
\text { Applying modified/new version of } \\
\text { training } \\
\text { Appraisal based on previous practices } \\
\text { Based on performance evaluation }\end{array}$ & $\begin{array}{l}\text { HR couldn't be } \\
\text { frequently used in all } \\
\text { orgs, as the } \\
\text { community resists and } \\
\text { fails to understand the } \\
\text { true spirit of HR }\end{array}$ \\
\hline Sri-Lanka & $\begin{array}{l}\text { Job Description } \\
\text { Recruitment } \\
\text { Compensation Benefits / } \\
\text { Rewards }\end{array}$ & $\begin{array}{l}\text { Minimal job definition } \\
\text { Traditional recruiting process } \\
\text { Traditional compensation policies; } \\
\text { based only on the visible performance }\end{array}$ & $\begin{array}{l}\text { HR functions are } \\
\text { merely based on the } \\
\text { human need rather } \\
\text { than employee } \\
\text { satisfaction }\end{array}$ \\
\hline
\end{tabular}


The above table depicts comparative measurements of the South Asian countries on their HR related practices. The countries are showing their internal differences in beliefs of $\mathrm{HR}$ activities. The details of above comparative table are discussed in ensuing paragraphs.

\subsubsection{Bangladesh}

Issuing authorities are always concerned about the modification of the policies and innovation of systems inside the organizations; they treat them as the HR activities inside the organization. Till now, Bangladeshi indigenous organizations are very confused with their HR policies and practices. Companies with international affiliation have a follow-through structure about HR practices in their organizations. Both indigenous organizations and MNCs lack one basic issue in HR, i.e. the implementation of HR policies and practices. At the implementation phase, all the companies face enormous fight back from the employees. Resistance is the first and the most dominant issue for HR practices in Bangladesh. Policy formulation and directing the policies are not very rare; rather it may be more relevant to say that policy formulation is quite frequent. True and timely implementation of the HR policies in the organizations is not taken seriously, in both indigenous (without standard HR policy) and MNC (with standard HR policy). Creating an HR model for Bangladesh is not tough but ensuring the model for its existence in the near future cannot be guaranteed. Bangladeshi managers are always enthusiastic about their personal improvement than the organizational growth and success. The situational factors have considerable influence on the decisions which are usually taken at the higher management level.

\subsubsection{Bhutan}

Public administration reforms, under the purview of the Royal Civil Service Commission, have focused on organization restructuring, human resource development, and the development of a Position Classification System (PCS). The PCS is an instrument for major reforms pertaining to human resources in the public service. In terms of human resource development, a considerable amount of training of public sector managers and administrators has been taking place, much of it being donor supported. But what is perhaps more important is that many managers have acquired higher education abroad which impacts professional standards and the capacity to formulate and realize reforms. At present, the challenge in HRD is to manage more in-country education and training. In terms of governance and public management, the Royal Institute of Management is currently enhancing its capacity and introducing different programs in public management education and training to comply with the requirements of the reform. Bhutanese managers having Masters in Public Administration and Finance degrees were envisaged early in 2008.

Most of the civil service organizations of Bhutan are still at the stage of shaping their HRM practices. In public sector, the HR practices, including recruitment, training, performance evaluation, career planning \& development and compensation \& reward system, are not specifically aligned with vision, mission and strategies. The head (also called Dasho) of a public sector organization hardly pays any attention to this aspect of job. The task of alignment of $\mathrm{HR}$ functions with vision and mission of the organization is assigned to the Royal Civil Service Commission (RCSC) or to the concerned civil organization. The former provides leadership and national policy planning systems across the civil-service and also supports government ministries, departments and agencies (Wangdhee, 2002). In 
the absence of suitable HR competence, the ongoing arrangement is not likely to work for a long term and individual organizations will have to formulate their own HR policies, strategies and practices within the broad civil service policy framework.

\subsubsection{India}

The conventional social philosophy from the earliest ancestry, which was urbanized over centuries, undergoes insightful alteration during the British regulation. Accordingly, in the modern context, manifold layers of principles (core traditional values, individual administrative standards, and situational standards) have emerged (Chatterjee \& Pearson, 2000). Although most of principles of society are to a large extent anchored in the traditional civilization, they are usually commercial priorities and principles of international linkages. However, in the context of globalization where priorities of consumerism, industrial education, mass media, overseas venture and a culture of employment amalgamation prevails, novel challenges are appearing obvious. As an example, Indian multinational companies which are said to be the worldwide firms are in the process of changing their importance to human resources, with their acquaintance and expertise, as the fundamental area of concentration in leveraging new performance limits (Khandekar\& Sharma, 2005).

The retiring age of employees in majority of the government sector firms is 55 to 58 years which means that apparently Indian youth is likely to have a control in public sector. Due to this, higher level Government agencies are seriously debating about increasing the retiring age limit, especially in education sector, hospitals, research institutions and municipal service sector. A promising governing perspective is that technological advancements have influenced the globalization in the areas like business, education, and communication. Infrastructures have a leading impact on mindsets of management and business attitudes. Striking changes take place for commercial mindsets and HRM strategies as a consequence of worldwide imperatives and associating changes in collective priorities.

In India, there has been a clear fast growing trend towards giving importance to the human resource (HR) in order to make them more result oriented as opposed to the culture of maintaining traditional status-quo. As a result, the companies like software services, pharmaceuticals, and biotechnology are trying to revamp themselves and achieve a sustained competitive advantage through HR.

\subsubsection{Maldives}

A noteworthy demographic attribute in the Maldives is that the inhabitants are very young close to one third of the inhabitants are in schools. The fast growing population, particularly in its capital city, 'Male' (where $25.5 \%$ of the total population lives), is a matter of great concern. According to the 1995 census, $17.3 \%$ of the population is under 5 years of age and $46.5 \%$ under 15 years of age. Therefore there is a large percentage of youth which poses severe challenge to improvement efforts, including stipulation of learning to the juvenile.

Maldives has improved its financial health and a lot of improvement has been made in the living standards in spite of expansion in inhabitants of $2.8 \%$ in the last five years. Tourism and fishery sectors are the major contributor towards economy. In 1997, the collective contribution of these two sectors, i.e. 'tourism and fisheries', was calculated to be $30 \%$ to the overall GDP. The ongoing improvement in the in subsidiary activities has enlarged significantly and this trend is expected to further add value since production of fishing vessels 
is being urbanized. The proficiency level obligatory to those occupied in the industry and Modern fishing techniques, which are well known as a supply of fishermen, the contribution of engineers in the form of diesel engines and refrigeration techniques, have transformed the work environment.

The consequence of fisheries segment in the countrywide market is considered to be an extreme human resource constraint and also the scarcity of competent managers, administrators, marine scientists and biologists, adequately trained technicians, research assistants and other trained mid level staff is a real threat. The country is trying to overcome this dearth by seeking services of neighboring countries. Tourism is the most flourishing sector that had a contribution of $19.1 \%$ to the total GDP in 1997. Tourism has emerged as the most important sector contributing in the national economy and it has overtaken the fishing industry. The schooling and instruction system of the country faces a great challenge towards the supply of adequate number of experienced workers in this field which is going to be a real threat to in the tourism industry. The country is still in the beginning stage as far as application of modern human resource practices is concerned.

\subsubsection{Nepal}

HRM practices in Nepal are no different than other developing countries in the region. Theoretical, in Nepal, employees are considered to be individuals having different goals and are not considered as basic corporate resource like trucks and filing cabinets. Employees are considered an important asset and it is assumed that virtually all wish to contribute to the enterprise but lack of knowledge, insufficient training, and failure to understand work process in Nepalese organizations is a source of low productivity.

HRM is considered as more modern and a creative component of employee management system which is very much refined and is different from the traditional approach. Its mechanism obliges the managers of a company to state their goals with specificity. The wherewithal required for them to effectively complete their coursework is too less to meet the requirement. So, when HRM techniques are properly practiced, they project true expression of the goals and different ventures follow the overall strategy. HRM is also helping the organizations by reducing the risk.

In Nepal, Government organizations are following a Performance Evaluation System in which higher level officers rate their subordinates by using multiple indicators. They submit a report in which individual's score is given to the appropriate sector head and at the end of the day to HRM department. The Recruitment Division, of HRM department, maintains all these scores and promotion decisions are also linked with these scores. The higher level officers do not assign too lofty objectives for the subordinates in advance at the beginning of the year. Usually, duties are assigned by the supervisors, as and when they need to be accomplished. In that case, senior officers evaluate their subordinates, using different appraisal techniques, on the criteria items like punctuality, diligence, loyalty, etc. Hence, in Nepali firms, the performance of the entire staff is not managed as a whole, as per a uniform criteria. Performance of employees is evaluated according to Key Performance Indicators (KPI). Indicators such as knowledge, punctuality, diligence, loyalty, attitude toward work, discipline, honesty, etc., are not considered while measuring performance or goal attainment (Pandit, 2009). 


\subsubsection{Pakistan}

In Pakistani context, HR is a newly developing department, especially in public sector organizations. Lot of resistance is displayed by the old employees and also from top management, who are not flexible in changing their old style traditional practices. The cause of resistance from top management is that they are of old mindset, treating HRM as an administrative activity done once a year and they are less willing to understand the true spirit of modern HRM. Instead of following a set of uniform HR practices, organizations have their own point of view. Usually, managers at the top of hierarchy pass the buck by transferring most of the problems to HR, including the ones which have no link at all. Whether problems relate to production, security, or any other functional area, they are attributed to the HR segment. In the absence of dedicated HR department, especially in public sector, its responsibilities are shared by other departments. When management decides to create a specific HR department, people in other departments are scared about their authority and think that perhaps they may lose their position and it often leads to conflicting situation. They, perhaps, do not realize that HR department works in their support as a support function of all other functional areas. However, they need to understand that through a dedicated HR department, they would receive a lot of assistance in formulating organizational structure, proper pay structure, promotion plans and employee compensation and benefits plans etc.

In most of the public sector companies, when top level managers perceive that most of the problems shall be resolved by HR department, then they establish it by hiring a suitably qualified HR Manager. HR policies are formulated by the new HR manager who ultimately bears the entire pressure all alone. He solves such kind of problems which are critical in nature and focuses especially on recruitment, training, separation, evaluations, increments etc. but he/she has to bear pressure from various directions. Top administration pressurizes him/her to show swift outcome and the HR person is left with perplexity about what is the right thing to do.

HR practices in Pakistani organizations are on the transition phase i.e. from traditional administrative style to the new style of managing HR policies, rules and procedures within the organization. While, almost all MNCs and many leading local private firms are following latest HR practices, Pakistani public sector still needs to gather sufficient momentum to match the pace of private sector. Efforts are being made to create awareness among the public sector about scope and benefits of modern HR practices. The brain drain of talented youth, which has risen to an alarming high level, has affected true implementation of HR practices in both private and public sectors. However, some initiatives are being taken at government level to reduce this brain drain but the progress is not significant.

\subsubsection{Sri-Lanka}

Sri Lanka is constrained by availability of limited talent and companies are facing a lot of problems in acquiring and placing right people for the right position. There is always an open war for Sri Lankan companies to get the right people, as lot of CVs are being received by them. For better jobs, a lot of imploring is involved and salary demands are soaring due to availability of limited number of right people for important positions. Another major problem is the brain drain which makes it difficult for the companies to fill serious interim talent gaps.

There is a serious need for perpendicular skills and organizations are looking for as close a fit as possible, by putting pressure on staffing consultants to shift the restricted talent from one corporation to another which is also a much source of concern for the HR 
managers. Organizations need to avert their business objectives languishing in the visage of scarcity of the exact talent and are indeed eager to give elevated compensation to potential candidates. Thus the organizations have been instinctive contributors to a huge raise in remuneration levels. In today's context a brilliant employee can be as precious and difficult to replace as a reliable client.

Organizations now require constructing talent at all stages for which people can make an enormous distinction in overall performance and continue to find loyal employees who may create a positive change. The major challenge for any corporation is to get appropriate people onboard and get the unsuitable ones off board. Appropriate employees automatically get into the matching seats and then channel their energies in right direction. The talents are the company's most valuable asset as they can maintain a sustained competitive edge over the competitors. Companies then need to build talent at all levels that can make a difference in organizational performance and continuously find people who can make a real difference.

This requires HR managers to bear even more pressure as they are now supposed to act as strategic partners as opposed their earlier status as personnel administrator. In this capacity they are called strategic business partners in recruiting, inspiring and retaining top aptitude.

In today's context companies have to work very hard to find good talent because there is a short supply of good talent. In order to find right talent with the right aptitude they need to make sure that they are offering very competitive reward package. Additionally, employees should be offered supportive culture, developmental opportunities and other competitive benefits that make the company a place where people want to stay for a long time.

\subsection{Proposed Models for South Asia}

Basic objective of all HR models is to draw a common phenomenon to establish the internal connectivity of the components in HR related studies and theories. The initial goal for the South Asian HR model will be to focus on basic HR activities in this region. The illustrative model in figure 4 depicts the relationship amongst different components of HR practices in this region. 
Figure 4

Common HRM Goals in SA Context

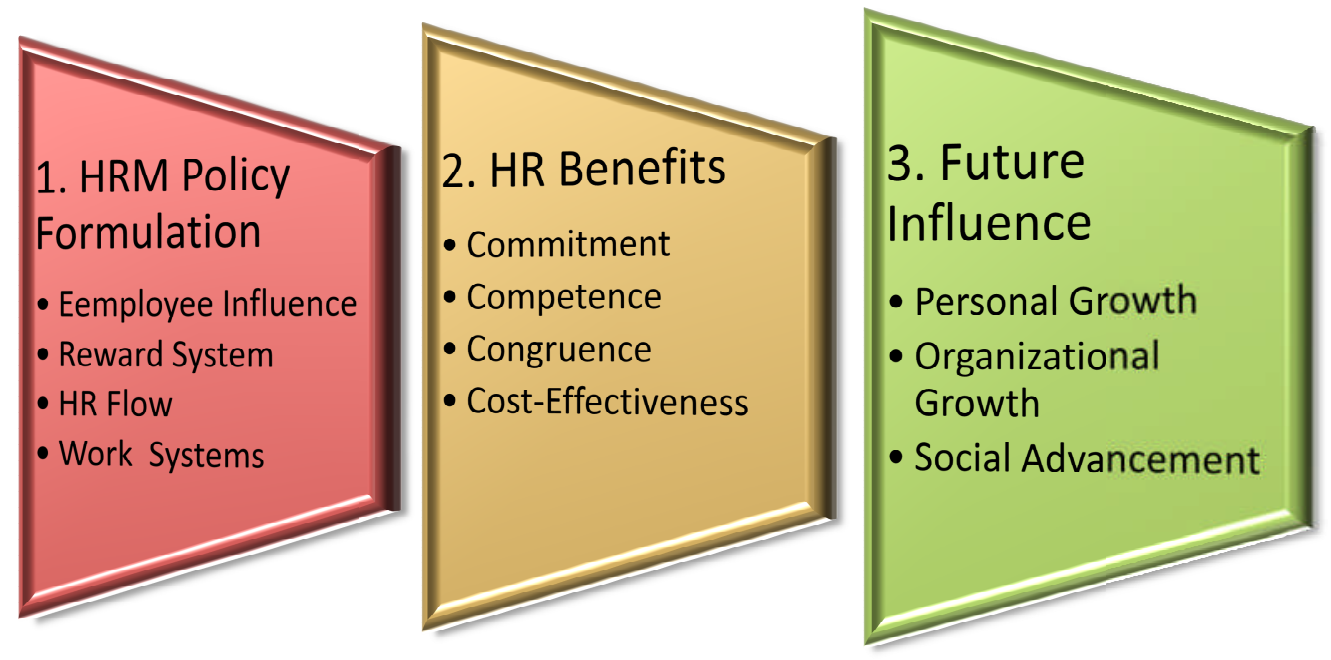

As per this three stage model, the initial HR activity begins with the formulation of HR policy. The concept is still very new and is gradually being adopted by many organizations one by one. Here the first step starts with the policy formulation, keeping in view influence of employees, their remuneration \& reward system, HR work flow inside the organization and overall system in place. To gain support of top management, the HR segment has to show outcome of the HR activities inside the organization. Here, 4Cs i.e. Commitment, Competence, Congruence, Cost-effectiveness (HR benefits) define various HR activities. Commitment is the term used to get the attention of both employees and the top management. Commitment can ensure growth of HR inside the organizational context. Competence is another issue where the organization is believed to be in the advanced stage of leading the industry. Though the organizational context is not always suitable to lead the industry tranquilly they achieve the power to be in better position than before through HR activities.

Another important topic is the similarity among organizations they are working with. It has been termed as 'Congruence'. The learning from the movement of another competing organization can help to achieve the landmark of being advanced at least in one sector than the others. Cost-effectiveness is the major issue for top management, as they are responsible to the investors or stakeholders of the organization to tell about the increased cost of HR movement inside the organization. So, HRD has to ensure advancement of the organization through monetary values using HR accounting or other compatible methods to get the summarized calculation.

The third and the last step is concerned with forecasting future achievements of the organization. Personal growth marks beginning of the future expansion of the organization. The personal benefits can ensure the highest possible outcome by the organization in all spheres. Secondly the organizational growth is achieved through accumulated effect of individuals' personal growth. The organizational growth further leads to future industrial advancement, where the HR policies are being implemented across the industry. Corporate Social Responsibility (CSR) is something ensured by the constant growth of the organization 
to become the pioneer of the industry in future. The social benefits have to be structured to meet social needs and wants.

\subsection{Existing HR Model of South Asia}

Illustrating South Asian model, limits some issues of HRM in the context to endure the standard approach of the managers towards the goal of the organization based on human related activities. The HRM practices in SA are a bit complex than the ones being practiced in the developed countries. The human capital is sometimes run by the exact HRM approach to fulfill the organizational needs and goals. But sometimes they deny showing the minimum respect to $\mathrm{HR}$ activities to support the organizational advancement due to their personal interests. Developing HR model for SA culture is challenging because of its divergent cultural and human values in different parts of this region. We have studied the smaller scale HR practices of individual seven countries in SA through early chapters; here the common practices will be stitched to get the picture of a common HR practice throughout the South Asian countries. A sample model of South Asian HR practices has been pictured below to further study the South Asian HRM culture.

Figure 5

Generalized Key Issues of HRM Model in South Asia

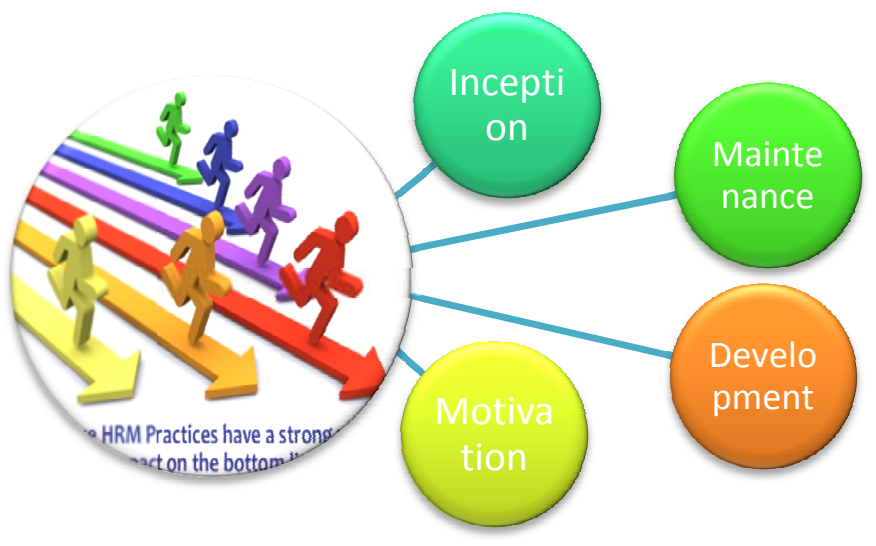

As depicted in figure 5, the initial criterion is the Inception - the initiator in the organization has to start the HR operation. The second criterion is Maintenance - to get through for shaping the concept in the initial context. The third criterion is Development the accumulator to reserve the power inside the organization to get the benefit of constant HR developmental process in local organizations. The fourth and last criterion is the Motivation which refers to the factor affecting employee involvement into the organizational HR activities to maintain the employee morale high in upcoming days to be succeeded in the relevant industry.

\subsection{Implementing Foreign Models in South Asia}

While implementing any foreign model, there is a need to look at the reason behind cultural variances. Here, it would be irrational to compare Eastern and Western cultures because there is no standard yardstick to precisely differentiate the two regions. As such, no standard foreign HR model can be replicated in South Asia, for its useful gains. As cited by Minkes (1994), there are cultural differences between China and Japan in the context of 
knowledge sharing and data dispensation. Similarly, there are differences in respect of ranking and power sharing in Britain and France, leading to diverse organizational practices (Foster \&Minkes, 1999).

There being lot of variance in the mindset and approach towards life and workplace, adopting any HRM model whether from developing or developed world shall not bare desired benefits because socio-cultural situation shall cause lot of resistance during the implementation stage of a model. People in Western world and for that matter, employees in organizations of developed countries in the West have strong internal locus of control whereas people in underdeveloped and developing countries feel that their fate is being controlled by the external forces that are out of their control. Accordingly, HRM practices are strongly influenced by their belief on external locus of control. In Western countries, HR is considered the most important resource and employees have a strong faith on their limitless potential for development and creativity.

\section{A CULTURE-BASED SOUTH ASIAN AND FOREIGN HRM MODEL}

Looking at implementation of HRM practices in Foreign and South Asian countries, the HRM model given in Figure 6 clearly explains the sequence of HRM practices. This process further explores the impact of external and internal environmental forces on HRM practices and their association with organizational effectiveness. While describing HRM practices, under the cultural influence, the model points out at different variables which can contribute towards achieving overall organizational goals. Amongst other factors, the salient ones are political, economical and social set up, that are counted as external factors. In a particular South Asian society, civilizing principles subsequently mould and shape the HRM practices.

Attitudes and behavior of people have lot of influence on how operations and functioning of a company are undertaken. The prevailing culture and socio-cultural ethical values have significant impact on organizational behavior (OB). This model is based on the OB model. The HRM practices can be viewed at three levels i.e. personal/individual level, group level and organization/system level.

The influence of HR practices on different determinants varies in accordance with existing culture and beliefs of a society. The practices which are most suitable in case of personal/individual level may not be so effective in case of group level and organization level. 
Figure 6

South Asian and Foreign HRM Model Illustration

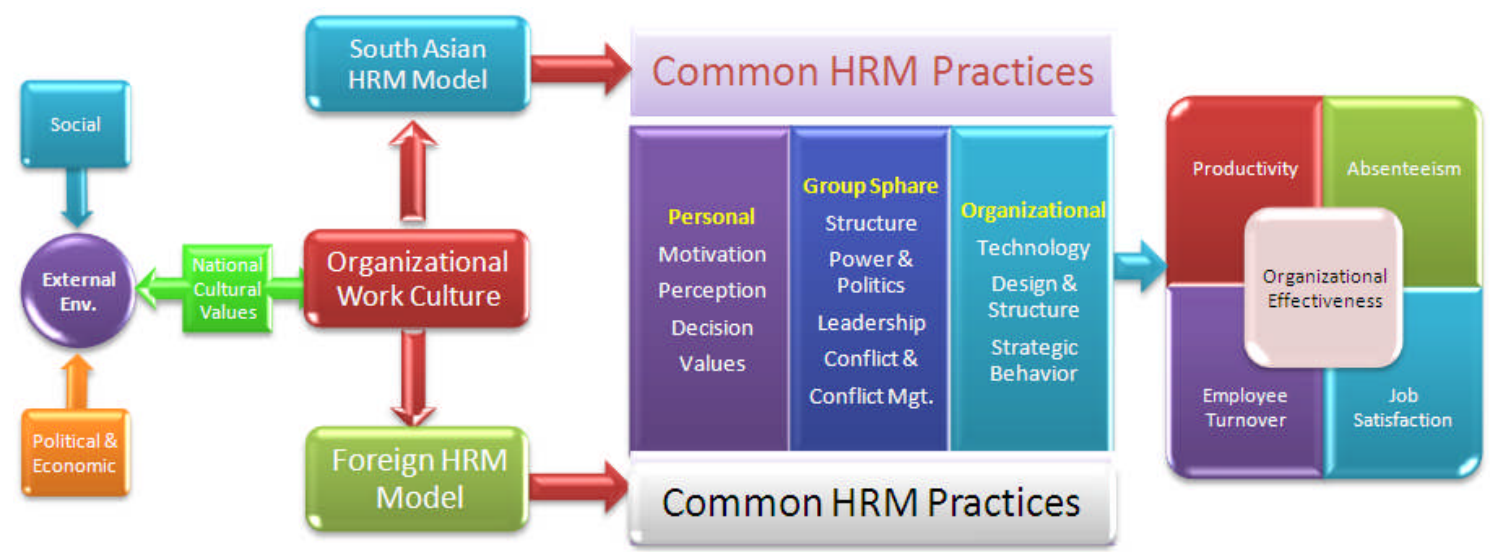

\subsection{Debate on Culture Oriented Indigenous HRM Practices}

People learn and develop their values, beliefs and attitudes right from their early life and continue to uphold for rest of their life, both in individual capacity and as a group. This is more applicable in case of South Asian region which has always been famous for its rich culture. HRM practices in South Asian organizations are quite heavily influenced by the culture. Behavior of employees is usually regulated by the cultural cues, at different levels of hierarchy and it is not easy to impose imported culture in its true shape.

\subsubsection{Foreign Model}

Like different cultures of the world that have their own set of values, traditions, ethics, customs etc., traditional Anglo-Saxon culture transformed into egalitarian form. As a result of this transformation, people migrated in abundance across many part of the globe. Although the print and electronic media have been portraying the negative results of egalitarianism, there are many advantages of egalitarian culture - inclination of people towards different sports is a true display of enthusiasm, potential, competitiveness and completion.

\subsubsection{South Asian Model}

In the context of South Asian region, cultural values are strictly followed by the people and employees limit themselves to the assigned duties. There is hardly any difference in approach towards workplace values and private life values. People do not display seriousness towards conformity towards professional values. The reason for this could be their belief about the predetermined and pre-decided life pattern; they feel that perhaps they cannot play any role in changing the life style because their fate has already been decided at the time of birth. This means that their belief in pre-determined fate drives them towards doing what is essentially required by the job description and their hard work is simply towards achieving excellent rewards and benefits. 


\subsection{Characteristics of HRM Practices}

\subsubsection{Foreign Model}

A debate about importance of tangible and intangible rewards is an ongoing topic. Almost in many foreign countries, employees consider that money is not such an important motivator; they believe that for better workplace environment, mutual cohesiveness and employee commitment to work are equally important. It is also a known fact that people leave an organization for taking up alternate jobs even for less money due to negative work relationships. This may be due to influence of a strong egalitarian culture of Australia.

\subsubsection{South Asian Model}

As per workplace spirituality, it is important not only to win heart and mind to ensure employee commitment and loyalty but also their soul i.e. the emotional side of human being is also quite important. As per employee perception of the western world, performance of duties is a way to release them from the shackles of resurrection. However, in the context of South Asia, the application of both tangible and/or intangible motivators should also focus on the employees' spirituality.

\section{FINDINGS}

The examples provided in this study explained the cultural reasons for indigenous HRM behavior, but these examples did not provide enough supportive statements to reveal the cultural basis for the culturally dominated Foreign HRM practices adopted in local organizations. This is because of imitation of culturally alien HRM practices or institutional transferability of HRM practices by multinational companies to their host country employees. Although the companies have a few culturally indigenous HRM practices, and more culturally influenced Foreign HRM practices, the managers in these companies have limited cultural understanding of those cultural Foreign HRM practices. This highlights the lack of 'emic' understanding of culturally influenced Foreign HRM practices, and hence, the diversity management in these companies is just based on 'etic' approach. The adoption of an 'etic' approach in diversity management is more common than the 'emic' approach.

\section{CONCLUSION AND IMPLICATIONS}

The research findings are limited because of the modest foreign available model and geographical area. Culture is important in understanding management behavior and organization systems, but other factors like political and economical structure, although quite important, were not vastly included in this study. Although HRM practices identified in this study tend to decrease mindless imitation/adaptation of western management practices, the present study can be replicated in countries in Asia Pacific region to document 'emic' understanding of companies. The study has indicated that there is a great impact of culture on HR practices in South Asia, due to presence of rich traditional values and traditions. The culturally indigenous HRM practices and culturally influenced Foreign HRM practices are found to a large extent in large companies in the South Asian region. Despite the organizational illustrations discovered by the available resources being a good source of qualitative understanding of culturally indigenous HRM practices, the findings lack through generalization; yet this area is a promising focus for further research. 
However, this study needs further expansion with an aim to establish the relationship between culturally indigenous HRM practices and organizational effectiveness. Additionally, there are two interesting lessons in this study regarding imitation of culturally influenced Foreign HRM practices in the host country companies. Firstly, continuous exposure of culturally influenced Foreign HRM practices by local companies to their employees can make such values as part of any established value systems of employees in all countries. Secondly, the stuff used in this study makes us believe that company's interests motivate culturally influenced Foreign HRM practices, and it does not matter whether it matches with the employees' value system or not. Moreover, the companies need to be ready to adopt latest HR trends so that they may be able to benefit from the ongoing HR practices at global level. Hence, future research may also focus on culturally indigenous HRM practices in small, medium and large indigenous companies in a host country, to limit the effect of institutional transferability of HRM practices among multinational companies. Such endeavors have the potential to highlight the impact of culturally indigenous HRM practices on organizational effectiveness, and aggrandize the importance of culturally indigenous HRM practices for companies in Asia Pacific region.

\section{REFERENCES}

Bhatnagar, R. (2007). India's Membership of ITER Project. Retrieved September 26, 2009, from Bangalore Press Information Bureau: http://www.pibbng.kar.nic.in/feature1.pdf

C. Venkatratnam, V. C. (1996). Sources of diversity and the challenge before human resource management in India. International Journal of Manpower, 17 (4/5), 76-96.

Chatterjee, S. R. (2007). Human Resource Management in India: 'Where From' and 'Where To?'. Research and Practice in Human Resource Management , 15 (2), 92-103.

Chatterjee, S., \& Pearson, C. (2000).Indian managers in transition: Orientations, work goals, values and ethics. Management International Review , 40 (1), 81-95.

Deyo, F. C. (1989). Beneath the miracle: Labor subordination in the new Asian industrialism. Los Angeles: University of California Press.

Foster, M., \&Minkes, A. (1999). East and West: Business culture as divergence and convergence. Journal of General Management, 25 (1), 60-71.

Guest, D. E. (1987).Human resource management and industrial relations. Journal of Management Studies , 24 (5), 503-521.

Khandekar, A., \& Sharma, A. (2005).Managing human resource capabilities for sustainable competitive advantage: An empirical analysis from Indian global organization. Education \& Training , 47 (48), 628-639.

Kuruvilla, S. (1996).Economic development and industrial relations: The case of South and South-East Asia. Industrial Relations Journal , 27 (1), 9-23.

Kuruvilla, S. (1996). Linkages between industrial nation strategies and industrial relations/human resource policies: Singapore, Malaysia, the Philippines and India. Industrial \&Labour Relations Review , 49 (4), 635-58.

M. Khasro Miah, M. W. (2003). Cross-cultural Comparisons of HRM Styles: Based on Japanese Companies, Japanese Subsidiaries in Bangladesh and Bangladeshi Companies. Global Business Review , 4 (1), 77-98.

Minkes, A. (1994). Making Asian Managers.Hong Kong: Management Development Centre of Hong Kong.

Pandit, K. (2009).Human Resource Management in Nepal Rastra Bank. Retrieved 
September 27, 2009, from South East Asian Central Banks Research and Training Center: http://www.seacen.org/publications/content/2009/rp75/6-chap5.pdf

Pawan S. Budhwar, Y. A. (Ed.). (2001). Human Resource Management in Developing Countires.London, Great Britain: Rutledge.

Peters, T. J., \& Waterman, R. H. (1982).In search of excellence, lessons from America's best run companies.New York: Harper and Row.

Rangarajan, L. (1992). The Arlhãshastra.New Dheli: Penguin Books.

Registrar General \& Census Commissioner, I. (2007). Retrieved September 26, 2009, from Census of India: http://www.censusindia.gov.in/

Sen Gupta, A. K., \& Sett, P. K. (2000). Industrial relations law, employment security and collective bargaining in India: Myths, realities and hopes. Industrial Relations Journal , 31 (2), 144-153.

Sharma, A., \&Khandekar, A. (2005). Managing human resource capabilities for sustainable competitive advantage: An empirical analysis from Indian global

organization. Education \&Training , 47 (47/48), 628-639.

Sihag, B. (2004). Kautilya on the scope and methodology of accounting, organizational design and role of ethics in ancient India. The Accounting Historians Journal , 31 (2), $125-148$.

Tichy, N., Fombrun, C., \&Devanna, M. A. (1982).Strategic human resource management. Sloan Management Review , 23 (2), 47-61.

Wangdhee, P. (2002, July). Making People Management a Strategic Organizational Purpose. Retrieved September 26, 2009, from dZinchongRigphel: http://www.rim.edu.bt/Publication/Archive/rigphel/rigphel1/index.htm 